OPEN ACCESS

Edited by:

Abhishek Ashok Solanki, Loyola University Chicago,

United States

Reviewed by:

Mengying Shi,

University of Massachusetts Lowell,

United States

Shisuo Du,

Fudan University, China

*Correspondence:

Jianbin Li

lijianbin@msn.com

Specialty section: This article was submitted to

Radiation Oncology,

a section of the journal

Frontiers in Oncology

Received: 10 September 2019 Accepted: 13 March 2020

Published: 09 April 2020

Citation:

Wang W, Wang J, Qiu P, Sun T, Zhang Y, Shao Q, XU M, Liu X and Li J

(2020) Factors Influencing the Incidental Dose Distribution in Internal

Mammary Nodes: A Comparative

Study. Front. Oncol. 10:456.

doi: $10.3389 /$ fonc. 2020.00456

\section{Factors Influencing the Incidental Dose Distribution in Internal Mammary Nodes: A Comparative Study}

\author{
Wei Wang ${ }^{1}$, Jinzhi Wang ${ }^{1}$, Pengfei Qiu ${ }^{2}$, Tao Sun ${ }^{3}$, Yingjie Zhang ${ }^{1}$, Qian Shao ${ }^{1}$, Min $X u^{1}$, \\ Xijun Liu ${ }^{1}$ and Jianbin i $^{1 *}$ \\ ${ }^{1}$ Department of Radiation Oncology, Shandong Cancer Hospital and Institute, Shandong First Medical University and \\ Shandong Academy of Medical Sciences, Jinan, China, ${ }^{2}$ Breast Cancer Center, Shandong Cancer Hospital and Institute, \\ Shandong First Medical University and Shandong Academy of Medical Sciences, Jinan, China, ${ }^{3}$ Department of Medical \\ Physics, Shandong Cancer Hospital and Institute, Shandong First Medical University and Shandong Academy of Medical \\ Sciences, Jinan, China
}

Objective: To investigate the effect of anatomic and technical parameters on the incidental internal mammary lymph node (IMN) irradiation (IIMNI) dose among postmastectomy patients.

Methods: We retrospectively delineated the IMN on planning CT images from 138 patients who had undergone postmastectomy radiotherapy (PMRT). We analyzed the IIMNI dose coverage and its relationship with anatomic and technical parameters.

Results: The IIMNI mean dose was $32.85 \pm 9.49 \mathrm{~Gy}$, and 10 of 138 patients $(7.25 \%)$ treated with PMRT received $\geq 45$ Gy. In univariate analysis, the body weight, body mass index, body surface area, thoracic transverse diameter $\left(D_{T}\right)$, ratio of $D_{T}$ to the thoracic anteroposterior diameter $\left(\mathrm{D}_{\mathrm{AP}}\right)\left(\mathrm{R}_{\mathrm{T} / \mathrm{AP}}\right)$, planning target volume of IMN (PTV $\left.\mathrm{V}_{\mathrm{IMN}}\right)$ included in PTV (IMNin) and the ratio of IMNin to PTV IMN $\left(\mathrm{R}_{\mathrm{IMNin}}\right)$ and PTV posterior border were the parameters affecting IIMNI dose. In multivariate analysis, body weight, $\mathrm{R}_{\mathrm{T} / \mathrm{AP}}$, and $\mathrm{R}_{\mathrm{IMN} \text { in }}$ were correlative factors that affected IIMNI dose.

Conclusions: For patients who underwent PMRT without IMN irradiation (IMNI), there was a wide variety in IIMNI doses. A minority of patients had adequate IIMNI dose coverage, and the higher IIMNI doses were associated with the less body weights and more $\mathrm{R}_{\mathrm{IMNin}}$.

Keywords: postmastectomy radiotherapy, internal mammary lymph node, incidental irradiation dose, anatomic parameters, technical parameters

\section{INTRODUCTION}

Irradiation of the chest wall and regional lymph nodes is considered the standard treatment strategy for breast cancer patients with positive axillary lymph nodes (ALNs) after mastectomy or modified radical mastectomy (MRM) due to its recognized success in improving local tumor control and overall survival (OS) (1-4). Internal mammary lymph nodes (IMNs) irradiation (IMNI) can improve disease-free survival (DFS) and OS in patients with breast cancer, and the mortality risk from ischemic heart disease with IMNI is equal to patients without IMNI $(5,6)$. However, in the 
Danish Breast Cancer Cooperative Group (DBCG)-IMN studies, patients with right-sided disease were allocated to the IMNI group, whereas left-sided patients were allocated to the no IMNI group (5). Therefore, potential bias might diminish the risk of radiation-induced heart disease. For the left-sided disease subset, one study that reviewed patients treated at a single institution from 1984 to 2007 showed no significantly increased hazard with IMN radiotherapy in planned three-dimensional conformal radiotherapy (3D-CRT) (7). Conversely, Taylor et al. reported a systematic review of heart doses from breast cancer radiation therapy studies published from 2003 to 2013 and concluded that IMNI doubled the typical heart dose (8). Long-term radiotherapy toxicity, especially heart toxicity, should be considered for patients with left-sided breast cancer in whom long-term survival is expected (9). In the contemporary irradiation techniques era, radiation-induced heart lesions are further lessened, and therapeutic drugs for heart and coronary artery disease are more diversified, so continued follow-up of cardiovascular disease induced by radiotherapy is still needed.

For patients with breast cancer (stage I, II, or III), observed IMN recurrence rate was $<1 \%$ after primary breast cancer treatment, even when the IMNs are not excised or irradiated $(6,10)$. Patients most likely benefit from systemic therapies and incidental regional node irradiation $(11,12)$. According to current guidelines (e.g., NCCN), the internal mammary region should be included when regional lymph node irradiation is performed. It seems questionable whether a sub-group [that IMN receive high doses during incidental IMNI (IIMNI)] benefits from omission of IMNI, since high doses in the organs at risk (OARs) (heart and lung), comparable to IMNI, must be expected for these patients. Several studies have demonstrated the contribution of insufficient incidental radiation doses to IMNs using 3D-CRT (13-17). Some patients may not need IMNI, and this can minimize the risk of distant radiotherapy-induced cardiotoxicity, but there is insufficient evidence at this time to define such subgroups in detail. Individual risk assessment and optimization includes calculation of different treatment plans in high risk patients to evaluate the dose to internal mammary region.

So far, several studies have evaluated axillary dose levels using different techniques, and found dose distribution was directly influenced by the breast volume and shape (18-21). Active breathing control $(\mathrm{ABC})$ technique can reduce the IMN coverage in left-sided breast cancer patients planned for postmastectomy radiation therapy (PMRT) (22). Both the dosimetric aspect and patient anatomy could eventually influence the regional lymph nodes of breast cancer. We postulated that patient anatomy and technical parameters are the potential factors influencing IIMNI dose variance, and aims to identify which patients receive adequate IMN doses (45-50 Gy) when IMNs were not included in the clinical target volume (CTV).

\section{MATERIALS AND METHODS}

\section{Patient Selection}

Patients were eligible if they had undergone PMRT and were newly diagnosed with histologically confirmed invasive stage
I, II, or III breast carcinoma. All patients were confirmed to have no clinical or pathological evidence of IMN involvement at the time of diagnosis, and IMNs were not included in the CTV. The institutional research ethics board of Shandong Cancer Hospital and Institute approved this study (SDTHEC201703014), and all methods were performed in accordance with the relevant guidelines and regulations. The requirement to obtain written informed consent from patients was waived due to the retrospective nature of the investigation (retrospective singleinstitution cohort study).

\section{Delineation of Target Volume and IMN}

The CTV of the chest wall and supraclavicular fossa (SCF) was delineated based on the Radiation Therapy Oncology Group (RTOG) breast cancer contouring atlas (online at: http:// www.rtog.org/CoreLab/ContouringAtlases/BreastCancerAtlas. aspx). The chest wall cranial border is variable, depending on contralateral breast size and patient position, and the border is clinically located at the base of the caudal border of the clavicle head. The medial border does not cross midline and is highly variable depending on mastectomy scar. The CTV posterior border was the junction of chest wall muscles and the rib or rib-pleural interface, depending on the $\mathrm{T}$ and $\mathrm{N}$ stage. The planning target volume (PTV) was generated by the addition of a 5-mm margin to the CTV in all directions. The PTV was limited by $0 \mathrm{~mm}$ from the skin, and the amount of lung could be trimmed according to physician discretion. A 5-mm bolus was used over the chest wall. The heart was contoured along with the pericardial sac. The superior aspect was begin at the level of the inferior aspect of the pulmonary artery passing the midline and extend inferiorly to the apex of the heart (online at: http://www. rtog.org/CoreLab/ContouringAtlases/RTOG1106OAR Atlas. aspx).

Throughout the study, the IMN CTV was defined by the same radiation oncologist. The IMN was also contoured according to the RTOG breast cancer contouring atlas: from the first to third intercostal spaces (ICS1-3) through the topography of the internal thoracic vessels. The IMN PTV $\left(\mathrm{PTV}_{\text {IMN }}\right)$ was designed to include an expansion of $5 \mathrm{~mm}$ around the IMN CTV. The same contouring atlas was followed to minimize the interobserver variability in the IMNs and achieve the most precise and objective comparison.

\section{Treatment Planning}

The prescription dose was $50 \mathrm{~Gy}$ in 25 fractions (2 Gy per fraction) to the PTV, 5 days per week, delivered for 5 weeks. The enrolled patients were treated with one of the three irradiation techniques described below.

\section{D-CRT}

The chest wall was treated with two opposite tangential fields using 6-MV photon beams and an ipsilateral SCF with a single anterior field. The criteria of the 3D-CRT plan ensured that at least $90 \%$ of the PTV received the prescription dose. 


\section{Field-In-Field Forward Intensity-Modulated Radiotherapy (F-IMRT)}

The chest wall treatment plan involved the use of a tangential field technique with static multileaf collimator segments, with two parallel-opposed tangential fields using 6-MV photon beams. Two to five segmented fields were manipulated to maintain dose delivery to OARs, such as the ipsilateral lung (IPSL), and the heart within normally accepted tolerances and to reduce the volumes of hot spots in the treatment field. Four to five fields were designed toward the SCF to guarantee dose uniformity. The criteria of the F-IMRT plan ensured that at least $95 \%$ of the PTV received the prescription dose.

\section{Inverse IMRT (I-IMRT)}

The common isocenter was located in the center of the PTV. The tangential field technique was set to the entire PTV, and additional $0^{\circ}$ and $40^{\circ}$ MLC segments were constructed toward the SCF. The criteria of the I-IMRT plan also ensured that at least $95 \%$ of the PTV received the prescription dose. Additional subfields were set to shield the areas of PTV receiving dose $>110 \%$ of the prescription dose, and keeping the dose delivered to OARs within normally accepted tolerances.

\section{Anatomy and Technical Factors}

Height, body weight, body mass index (BMI), and body surface area (BSA), T- and $\mathrm{N}$-stage were documented in all patients when available from clinical records. In the transverse view of the planning CT images, the number of internal thoracic vessels were counted, and the distance between the most anterior limit of the thoracic vertebrae and the most posterior limit of the sternum in the uppermost level of the inferior vena cava was measured and defined as the thoracic anteroposterior diameter $\left(\mathrm{D}_{\mathrm{AP}}\right)$. Thoracic transverse diameter $\left(\mathrm{D}_{\mathrm{T}}\right)$ was the greatest horizontal distance of the inner wall of the thorax from the uppermost level of the inferior vena cava. The ratio of $\mathrm{D}_{\mathrm{T}}$ to $\mathrm{D}_{\mathrm{AP}}$ was defined as $\mathrm{R}_{\mathrm{T} / \mathrm{AP}}$.

Both CTV and PTV volumes, PTV IMN volume and PTV $\mathrm{PMN}_{\text {IMN }}$ volume included in PTV (IMNin) were obtained through the Eclipse treatment planning system (TPS) (Eclipse 13.5; Varian Medical Systems, Palo Alto, CA). And the ratio of IMNin to $\mathrm{PTV}_{\text {IMN }}\left(\mathrm{R}_{\mathrm{IMNin}}\right)$ was calculated as $\mathrm{R}_{\mathrm{IMNin}}=\mathrm{IMNin} / \mathrm{PTV}_{\mathrm{IMN}}$. As potential factors, CTV and PTV borders, wedge shaped plate, SCF, and irradiation technique were also documented in all patients. Gantry angles ranged from 39 to $60^{\circ}$ for the medial fields and from 220 to $253^{\circ}$ for the lateral fields for right-sided PTV, and the gantry angles ranged from 300 to $320^{\circ}$ for the medial fields and from 115 to $140^{\circ}$ for the lateral fields for left-sided PTV. The angle between the medial field gantry angle and horizontal line may also be critical in affecting the IIMN dose and was defined as an incident angle. For right-sided breast cancer patients, this angle is equal to the gantry angles for the medial fields, while for left-sided breast cancer patients, this angle is equal to gantry angle minus $180^{\circ}$.

\section{Statistical Analysis}

Statistical analysis was performed with the SPSS statistical analysis software package. Based on the normality of the distributions, $t$-tests or one-way analysis of variance (ANOVA) was used to assess the statistical significance of the differences between the covariates. Univariate regression analysis and multiple regression analysis were used to assess the relationship between IIMNI dose differences and a set of covariates, such as body weight, BMI, BSA, and radiotherapy technique. All tests were two-sided. Results were regarded as statistically significant when $p<0.05$.

\section{RESULTS}

\section{Patients and Treatments}

One hundred and thirty-eight breast cancer patients who underwent PMRT between 2012 and 2016 were enrolled in this retrospective study. Table 1 outlines the patient and treatment characteristics. None of the patients received radiotherapy to the ipsilateral IMN.

TABLE 1 | Patient characteristics and treatment variables.

\begin{tabular}{|c|c|c|}
\hline Characteristic & $n$ & $\%$ \\
\hline \multicolumn{3}{|l|}{ Age (y) } \\
\hline Minimum & 25 & 18.12 \\
\hline Maximum & 74 & 53.62 \\
\hline Median & 47 & \\
\hline \multicolumn{3}{|l|}{ Histology } \\
\hline Invasive ductal carcinoma & 134 & 97.10 \\
\hline Invasive lobular carcinoma & 3 & 2.17 \\
\hline Invasive papillary carcinoma & 1 & 0.72 \\
\hline \multicolumn{3}{|l|}{ Tumor location } \\
\hline Left-sided & 73 & 52.90 \\
\hline Right-sided & 65 & 47.10 \\
\hline \multicolumn{3}{|l|}{ T stage } \\
\hline TO & 2 & 1.45 \\
\hline $\mathrm{T} 1$ & 39 & 28.26 \\
\hline $\mathrm{T} 2$ & 79 & 57.25 \\
\hline T3 & 11 & 7.97 \\
\hline T4 & 6 & 4.35 \\
\hline Tx & 1 & 0.72 \\
\hline \multicolumn{3}{|l|}{ N stage } \\
\hline NO & 6 & 4.35 \\
\hline N1 & 46 & 33.33 \\
\hline N2 & 52 & 37.68 \\
\hline N3 & 33 & 23.91 \\
\hline $\mathrm{Nx}$ & 1 & 0.72 \\
\hline \multicolumn{3}{|l|}{ Radiotherapy } \\
\hline 3D-CRT & 48 & 34.78 \\
\hline F-IMRT & 49 & 35.51 \\
\hline I-IMRT & 41 & 29.71 \\
\hline \multicolumn{3}{|l|}{ PTV } \\
\hline Chest wall & 7 & 5.07 \\
\hline Chest wall+SCF & 131 & 94.93 \\
\hline
\end{tabular}

SCF, supraclavicular fossa; 3D-CRT, three-dimensional conformal radiotherapy; F-IMRT, field-in-field forward intensity-modulated radiotherapy; I-IMRT, inverse IMRT. 


\section{Incidental IMN Dose Coverage}

The mean dose for the PTV IMN was $32.85 \mathrm{~Gy}$ for all patients (SD, $9.49 \mathrm{~Gy}$ ), ranged from $2.76 \mathrm{~Gy}$ (Figure 1a) to $50.93 \mathrm{~Gy}$ (Figure 1b). There were no significant differences between right breast cancer patients and left breast cancer patients (34. 41 $\pm 9.14 \mathrm{~Gy}$ vs. $32.09 \pm 9.68 \mathrm{~Gy}$ ). Adequate coverage of the $\mathrm{PTV}_{\text {IMN }}$, defined as $\geq 45 \mathrm{~Gy}$, was achieved for 10 out of the 138 breast cancer patients with PMRT (7.25\%). The clinical and anatomic parameters influencing doses to IMNs are summarized in Table 2. Patients were separated according to IIMNI dose $\geq 45 \mathrm{~Gy}$ and $<45 \mathrm{~Gy}$, and body weight, $\mathrm{BMI}, \mathrm{BSA}$, and $\mathrm{D}_{\mathrm{T}}$ were found to be lower in patients with IIMNI dose $\geq 45$ Gy than in patients with IIMN dose $<45$ Gy. While the higher IIMNI doses were associated with the more IMNin and $\mathrm{R}_{\mathrm{IMNin}}$. Patient height, $\mathrm{D}_{\mathrm{AP}}, \mathrm{R}_{\mathrm{T} / \mathrm{AP}}$, number of internal thoracic vessels, CTV volume, PTV $\mathrm{IMN}_{\mathrm{IMN}}$ volume, CTV and PTV border, and gantry angles showed no significant differences between the two groups. There was also no difference in the number of patients using a wedge-shaped plate for patients who underwent 3D-CRT; while $50 \%$ of the patients received an IIMNI dose $\geq 45$ Gy using a wedge-shaped plate, only $23.26 \%$ of the patients received an IIMNI dose $<45$ Gy using a wedge-shaped plate.

\section{Factors Related to IIMNI Dose Changes}

A summary of the factors influencing the IIMNI dose is shown in Table 3. In the univariate analysis, the IIMN dose was significantly higher in patients with lower body weight, BMI, BSA, $\mathrm{D}_{\mathrm{T}}$, higher $\mathrm{R}_{\mathrm{T} / \mathrm{AP}}$, IMNin, $\mathrm{R}_{\mathrm{IMNin}}$, and whose PTV posterior border was intrapulmonary. There were no significant relationships observed between the Dmean of the IIMNI dose and the magnitude of patient height, $\mathrm{D}_{\mathrm{AP}}$, number of internal thoracic vessels, CTV/PTV/PTV IMN volume, CTV/ PTV border, gantry angles, T-stage, N-stage, or the radiation delivery technique for all patients. In multivariate analysis, three variables remained significant; thus, body weight, $R_{T / A P}$, and $\mathrm{R}_{\mathrm{IMNin}}$ were the correlative factors that affected IIMNI dose (Table 3).

\section{DISCUSSION}

Extended resection of the IMNs, which can jeopardize the survival of breast cancer patients even more than the breast cancer itself, has been abandoned (23). IMNI has been shown to have a significant impact on locoregional control, breast cancer mortality, and OS (5-7), but controversies concerning IMNI still exist, mainly because of radiotherapy-induced longterm lung and heart toxicity $(8,24,25)$. Though the incidental dose to the IMNs not achieve clinically significant therapeutic levels $(26,27)$, recent studies have demonstrated that accepting adequate doses during incidental irradiation can result in a clinical benefit $(6,10)$. By determining the variability in the IIMNI dose coverage with standard chest wall tangential fields

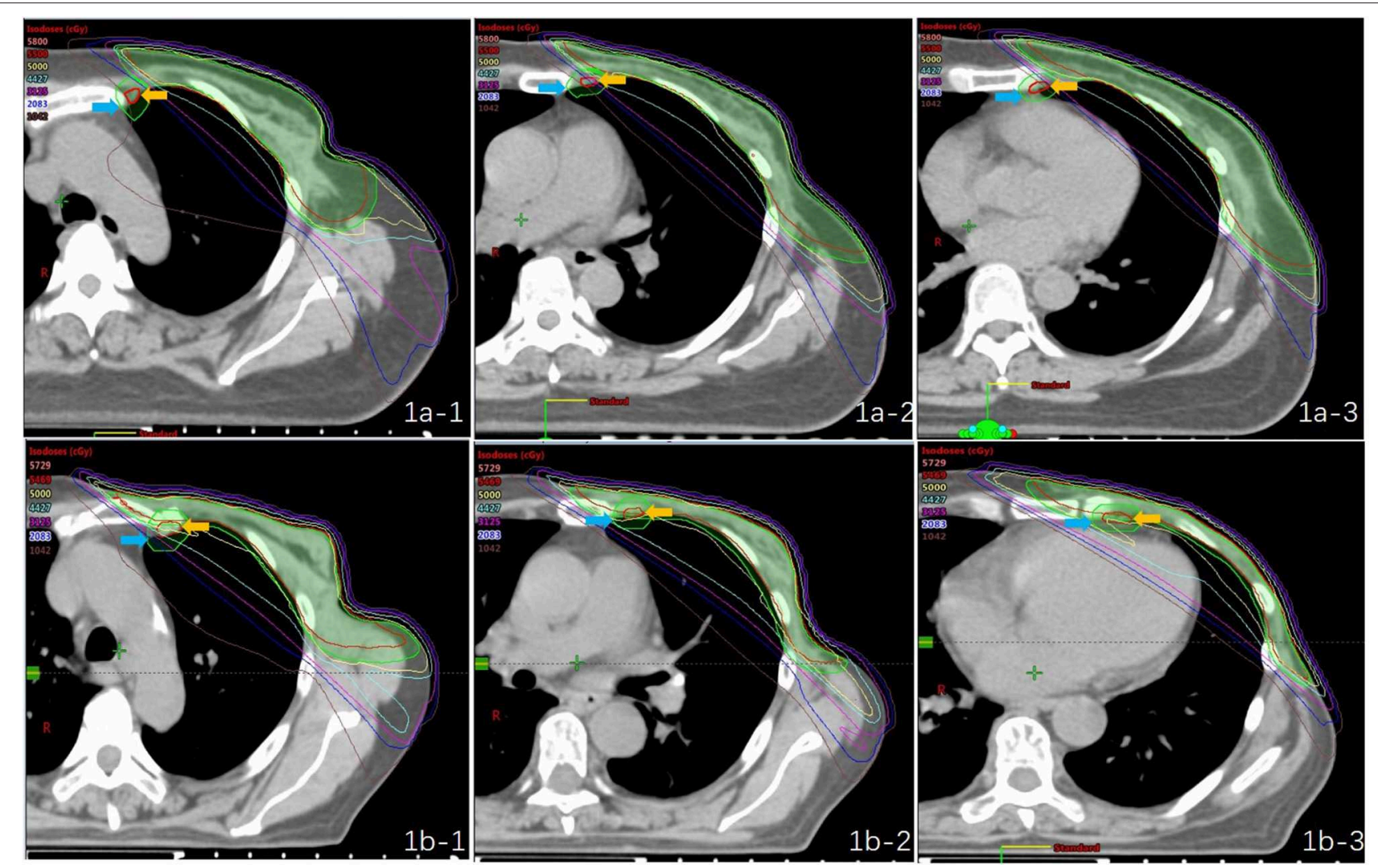

FIGURE 1 | Treatment plans and dose distribution of two "extreme" patients [(a) PTVIMN was 2.76 Gy; (b) PTVIMN was 50.93 Gy; -1: first intercostal space,-2: second intercostal space,-3: third intercostal space; yellow arrow: the IMN CTV; blue arrow: the IMN PTV]. 
TABLE 2 | Comparison of covariates between patients with and without adequate IMN coverage.

\begin{tabular}{|c|c|c|c|c|c|}
\hline \multicolumn{2}{|c|}{ Characteristic } & \multirow{2}{*}{$\begin{array}{c}\text { Total } \\
138\end{array}$} & \multirow{2}{*}{$\begin{array}{c}\geq \mathbf{4 5} \text { Gy } \\
10\end{array}$} & \multirow{2}{*}{$\begin{array}{c}<\mathbf{4 5} \text { Gy } \\
128\end{array}$} & \multirow[t]{2}{*}{$p$-value } \\
\hline Number of patients & & & & & \\
\hline \multirow[t]{2}{*}{ Cancer laterality } & Right & 67 (48.55\%) & $3(30 \%)$ & $64(50 \%)$ & 0.909 \\
\hline & Left & $71(51.45 \%)$ & 7 (70\%) & $64(50 \%)$ & \\
\hline \multirow[t]{2}{*}{ Height (cm) } & Mean & 160.16 & 158.7 & 160.27 & 0.441 \\
\hline & SD & 5.54 & 4.79 & 5.59 & \\
\hline \multirow[t]{2}{*}{ Body weight (kg) } & Mean & 66 & 58.6 & 66.57 & 0.002 \\
\hline & SD & 8.83 & 4.485 & 8.84 & \\
\hline \multirow[t]{2}{*}{ BMl } & Mean & 25.74 & 23.36 & 25.93 & 0.010 \\
\hline & SD & 3.30 & 2.70 & 3.27 & \\
\hline \multirow[t]{2}{*}{ BSA } & Mean & 1.67 & 1.57 & 1.68 & 0.007 \\
\hline & SD & 0.13 & 0.05 & 0.13 & \\
\hline \multirow[t]{2}{*}{$\mathrm{D}_{\mathrm{AP}}(\mathrm{cm})$} & Mean & 10.01 & 9.71 & 10.04 & 0.438 \\
\hline & SD & 1.27 & 1.49 & 1.26 & \\
\hline \multirow[t]{2}{*}{$\mathrm{D}_{\mathrm{T}}(\mathrm{cm})$} & Mean & 23.25 & 22.71 & 23.29 & 0.043 \\
\hline & SD & 1.24 & 0.38 & 1.28 & \\
\hline \multirow[t]{2}{*}{$\mathrm{R}_{\mathrm{T} / \mathrm{AP}}(\%)$} & Mean & 43.21 & 42.77 & 43.25 & 0.796 \\
\hline & SD & 6.28 & 6.84 & 6.27 & \\
\hline \multirow[t]{2}{*}{ Internal thoracic vessels, $n$} & 2 & $128(92.75 \%)$ & $9(90 \%)$ & 119 (92.97\%) & 0.728 \\
\hline & 3 & $10(7.25 \%)$ & $1(10 \%)$ & $9(7.03 \%)$ & \\
\hline \multirow[t]{2}{*}{ CTV volume $\left(\mathrm{cm}^{3}\right)$} & Mean & 436.71 & 409 & 438.88 & 0.622 \\
\hline & SD & 138.16 & 90.2 & 141.24 & \\
\hline \multirow[t]{2}{*}{ PTV IMN volume $\left(\mathrm{cm}^{3}\right)$} & Mean & 29.44 & 28.92 & 29.48 & 0.748 \\
\hline & SD & 5.33 & 4.27 & 5.43 & \\
\hline \multirow[t]{2}{*}{ IMNin $\left(\mathrm{cm}^{3}\right)$} & Mean & 5.61 & 13.33 & 5.00 & 0.000 \\
\hline & SD & 4.88 & 3.54 & 4.45 & \\
\hline \multirow[t]{2}{*}{$\mathrm{R}_{\mathrm{IMNin}}(\%)$} & Mean & 18.92 & 46.33 & 16.78 & 0.000 \\
\hline & SD & 15.93 & 11.80 & 14.14 & \\
\hline \multirow[t]{3}{*}{ Irradiation technique, $n$} & 3D-CRT & 48 (34.78\%) & $5(50 \%)$ & 43 (33.59\%) & 0.112 \\
\hline & F-IMRT & 49 (35.51\%) & $1(10 \%)$ & 48 (37.50\%) & \\
\hline & I-IMRT & $41(29.71 \%)$ & 4 (40\%) & 37 (28.91) & \\
\hline \multirow[t]{2}{*}{ SCF, $n$} & Yes & $131(94.93 \%)$ & $10(100 \%)$ & $121(94.53 \%)$ & 0.449 \\
\hline & No & 7 (5.07\%) & $0(0)$ & $7(5.47 \%)$ & \\
\hline \multirow[t]{2}{*}{ Cranial border (CTV), $n$} & Clinical reference + second rib insertion & 65 (47.10\%) & $4(40 \%)$ & $61(47.66 \%)$ & 0.642 \\
\hline & Caudal border of the clavicle head & 73 (52.90\%) & $6(60 \%)$ & $67(52.34 \%)$ & \\
\hline \multirow[t]{3}{*}{ Medial border (CTV), $n$} & Midline & 33 (23.91\%) & $5(50 \%)$ & 27 (21.26\%) & 0.190 \\
\hline & Sternal-rib junction & $78(56.52 \%)$ & $3(30 \%)$ & 75 (59.06\%) & \\
\hline & In between & $27(19.57)$ & $2(20 \%)$ & 25 (19.68\%) & \\
\hline \multirow[t]{2}{*}{ Posterior border (PTV), $n$} & Intrapulmonary & $78(56.52 \%)$ & $8(80 \%)$ & $70(54.69 \%)$ & 0.121 \\
\hline & Rib-pleural interface & $60(43.48 \%)$ & $2(20 \%)$ & $58(45.31 \%)$ & \\
\hline \multirow[t]{2}{*}{ Wedge shaped plate, $n$} & Yes & $15(31.25 \%)$ & $5(50 \%)$ & $10(23.26 \%)$ & 0.069 \\
\hline & No & $33(68.75 \%)$ & $5(50 \%)$ & 33 (76.74\%) & \\
\hline Incident angles $\left(^{\circ}\right)$ & Mean & 52.64 & 52.3 & 52.66 & 0.993 \\
\hline
\end{tabular}

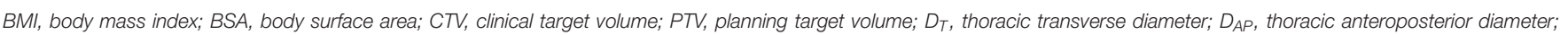
SCF, supraclavicular fossa; PTVIMN, planning target volume of IMN; IMNin, PTVIMN included in PTV.

using surface anatomy (as determined by a planning CT image) and in patients showing IMN drainage on lymphoscintigraphy, Proulx et al. showed that only $14 \%$ and $19 \%$ of patients had IMNs completely within the tangent fields $(28,29)$. Our study found significant variability in individual IIMNI dose for patients who accepted PMRT, and only $7.25 \%$ of the patients received a meaningful IIMNI dose when the IMNs were not included in the PTV. This led us to realize that even though low mean doses were being reported, there was significant dose inhomogeneity in the IMNs. The incidental dose to the IMNs may change according to body habitus according to Proulx et al. (28). These authors reported that presternal fat thickness 
TABLE 3 | Univariate and multivariate regression analysis of IIMN dose difference.

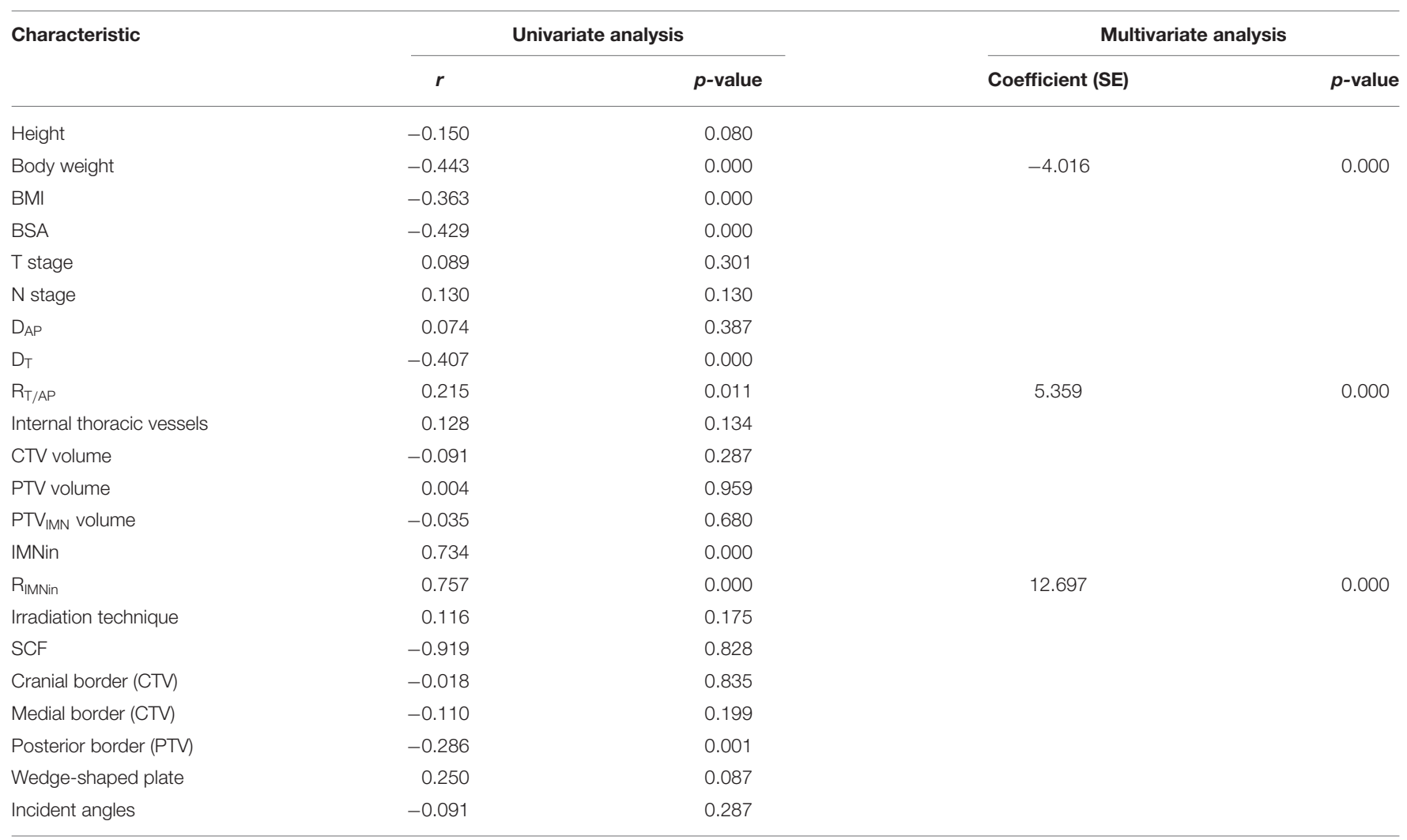

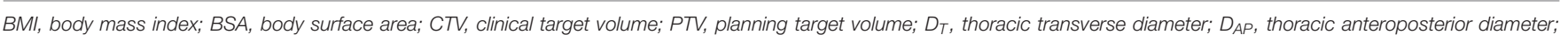
SCF, supraclavicular fossa; PTVIMN, planning target volume of IMN; IMNin, PTVIMN included in PTV.

was inversely correlated with IMN inclusion in tangent fields, while thoracic skeletal shape was not associated with IMN inclusion. These studies used the patient presternal fat thickness as a surrogate for body habitus, whereas the present study evaluated the influence of patient height, body weight, BMI, $\mathrm{BSA}$, the thoracic anteroposterior diameter $\left(\mathrm{D}_{\mathrm{AP}}\right)$, the thoracic transverse diameter $\left(\mathrm{D}_{\mathrm{T}}\right)$, and $\mathrm{R}_{\mathrm{T} / \mathrm{AP}}$ on the IIMNI dose to the patients who accepted PMRT. We postulated that patient anatomy and technical parameters were the potential factors influencing IIMNI dose variance and attempted to determine whether the combination of such influencing factors could potentially indicate a subgroup of patients in whom it would be appropriate to avoid IMN radiotherapy.

According to Sapienza et al. (14) and Arora et al. (15), the predictor for incidental dose to the IMNs is the Tstage and $\mathrm{N}$-stage of the tumor. These authors revealed that advanced $\mathrm{N}$ - and $\mathrm{T}$-stage involvement was correlated with higher average doses to IMNs. However, these results are contrary to those of the present study, in which both univariate and multivariate analyses confirmed that the $\mathrm{T}$-stage and $\mathrm{N}$-stage of tumors showed no correlations with the IIMNI dose. This variance may partly be due to the fact that some of the patients enrolled in the previous studies were early breast cancer patients who accepted BCS, and different operative approaches result in variance of presternal fat thickness, which was associated with IMN inclusion (28), and the radiation oncologists considered the patients to be at high risk and adjusted the fields accordingly.

Significantly decreasing the irradiation dose delivered to OARs (lung, heart, and spinal cord), IMRT improves the accuracy of breast cancer radiotherapy (30-32). While the IIMNI dose were consistent, regardless of the irradiation technique (3D-CRT: $33.80 \mathrm{~Gy}$, F-IMRT: 29.65 Gy, and I-IMRT: $32.95 \mathrm{~Gy}$, respectively) (26). Similar to Sapienza et al. (14), we observed that the addition of SCF field irradiation did not significantly increase the Dmean of the IMNs in the PMRT patients. Regardless of the radiotherapy technique, patient anatomy and clinical factors could eventually influence the dose distribution. Previous studies have associated body habitus with nodal volume dose distribution when breast cancer irradiation is administered $(20,33)$. The results of these present study showed that obese or overweight patients had poorer dose coverage with fixed depth prescription than normal weight patients, and higher doses were associated with the more voluminous $(\geq 1,200 \mathrm{cc})$ and pendulous breasts. Barry et al. (22) found no direct correlation between BMI and any IMN dosimetric parameter during both free breathing and active breathing control in 50 left-sided breast cancer patients. And this result is consistent with our findings, BMI is not sufficient to predict IIMNI dose, which was insignificant in the multivariate analysis (Table 3 ).

This analysis showed the higher IIMNI doses were associated with the less body weights and more $\mathrm{R}_{\mathrm{IMNin}}$. However, only 
10 patients received a meaningful incidental irradiation dose during PMRT, and thus, this sample size was insufficient to acquire a more clinically significant difference that would warrant identification of a subgroup of patients for whom it may be more appropriate to avoid IMNI for further management. Additional studies with a larger sample size are needed to provide more continuous up-to-date information.

\section{CONCLUSION}

The present analysis showed that a small number of breast cancer patients had adequate IIMNI dose coverage for postmastectomy chest wall \pm SCF irradiation, which might contribute to controlling IMN micrometastases. The patient body weights, $\mathrm{R}_{\mathrm{T} / \mathrm{AP}}$, and $\mathrm{R}_{\mathrm{IMNin}}$ was the most important influence factor for IIMNI doses. The risk of avoiding IMNI is different for PMRT patients with different body habitus in breast cancer subpopulations with a high risk of metastatic or even microscopic metastatic IMNs.

\section{DATA AVAILABILITY STATEMENT}

The datasets used and analyzed during the current study are available from the corresponding author on reasonable request.

\section{ETHICS STATEMENT}

The studies involving human participants were reviewed and approved by The institutional research ethics board

\section{REFERENCES}

1. Recht A, Edge SB, Solin LJ, Robinson DS, Estabrook A, Fine RE, et al. American society of clinical oncology. postmastectomy radiotherapy: clinical practice guidelines of the american society of clinical oncology. J Clin Oncol. (2001) 19:1539-69. doi: 10.1200/JCO.2001.19.5.1539

2. Ragaz J, Olivotto IA, Spinelli JJ, Phillips N, Jackson SM, Wilson $\mathrm{KS}$, et al. Locoregional radiation therapy in patients with high-risk breast cancer receiving adjuvant chemotherapy: 20-year results of the British Columbia randomized trial. J Natl Cancer Inst. (2005) 97:116-26. doi: 10.1093/jnci/djh297

3. EBCTCG (Early Breast Cancer Trialists' Collaborative Group), McGale P, Taylor C, Correa C, Cutter D, Duane F, et al. Effect of radiotherapy after mastectomy and axillary surgery on 10-year recurrence and 20year breast cancer mortality: meta-analysis of individual patient data for 8135 women in 22 randomised trials. Lancet. (2014) 383:2127-35. doi: 10.1016/S0140-6736(14)60488-8

4. Recht A, Comen EA, Fine RE, Fleming GF, Hardenbergh PH, Ho AY, et al. Postmastectomy radiotherapy: an american society of clinical oncology, american society for radiation oncology, and society of surgical oncology focused guideline update. J Clin Oncol. (2016) 34:4431-42. doi: 10.1200/JCO.2016.69.1188

5. Thorsen LB, Offersen BV, Danø H, Berg M, Jensen I, Pedersen AN, et al. DBCG-IMN: a population-based cohort study on the effect of internal mammary node irradiation in early node-positive breast cancer. J Clin Oncol. (2016) 34:314-20. doi: 10.1200/JCO.2015.63.6456

6. Poortmans PM, Collette S, Kirkove C, Van Limbergen E, Budach V, Struikmans $\mathrm{H}$, et al. EORTC radiation oncology and breast cancer groups. internal mammary and medial supraclavicular irradiation in breast cancer. $N$ Engl J Med. (2015) 373:317-27. doi: 10.1056/NEJMoa1415369 of the Shandong Tumor Hospital Ethics Committee (SDTHEC201703014). Written informed consent for participation was not required for this study in accordance with the national legislation and the institutional requirements. Written informed consent was not obtained from the individual(s) for the publication of any potentially identifiable images or data included in this article.

\section{AUTHOR CONTRIBUTIONS}

WW and JL participated in the study design, and contributed to the data collection, and draft the manuscript. TS, YZ, MX, and QS participated in the treatment planning. JW, PQ, and XL made important contributions in collecting and analyzing data, and in revising the content. All authors read and approved the final manuscript.

\section{FUNDING}

This work was supported by the National Natural Science Foundation of China (grant number 81703038); and the Key Research Development Program of Shandong Province (grant number 2019GSF108104); Bethune Charitable Foundation Shared Sunshine-Major Disease Clinical Research Project (grant number G-X-2019-0101-12).

\section{ACKNOWLEDGMENTS}

This manuscript was edited by American Journal Experts (AJE).

7. Dess RT, Liss AL, Griffith KA, Marsh RB, Moran JM, Mayo C, et al. Ischemic cardiac events following treatment of the internal mammary nodal region using contemporary radiation planning techniques. Int J Radiat Oncol Biol Phys. (2017) 99:1146-53. doi: 10.1016/j.ijrobp.201 7.06.2459

8. Taylor CW, Wang Z, Macaulay E, Jagsi R, Duane F, Darby SC. Exposure of the heart in breast cancer radiation therapy: a systematic review of heart doses published during 2003 to 2013. Int J Radiat Oncol Biol Phys. (2015) 93:845-53. doi: 10.1016/j.ijrobp.2015.07.2292

9. Boekel NB, Jacobse JN, Schaapveld M, Hooning MJ, Gietema JA, Duane FK, et al. Cardiovascular disease incidence after internal mammary chain irradiation and anthracycline-based chemotherapy for breast cancer. $\mathrm{Br} J$ Cancer. (2018) 119:408-18. doi: 10.1038/s41416-018-0159-x

10. Xie L, Higginson DS, Marks LB. Elective regional nodal irradiation in patients with early-stage breast cancer. Semin Radiat Oncol. (2011) 21: 66-78. doi: 10.1016/j.semradonc.2010.08.006

11. Giuliano AE, McCall L, Beitsch P, Whitworth PW, Blumencranz P, Leitch $\mathrm{AM}$, et al. Locoregional recurrence after sentinel lymph node dissection with or without axillary dissectionin patients with sentinel lymph node metastases: the American College of Surgeons Oncology Group Z0011 randomized trial. Ann Surg. (2010) 252:426-32. doi: 10.1097/SLA.0b013e3181 f08f32

12. Krag DN, Anderson SJ, Julian TB, Brown AM, Harlow SP, Costantino JP, et al. Sentinel-lymph-node resection compared with conventional axillary-lymphnode dissection in clinically node-negative patients with breast cancer: overall survival findings from the NSABP B-32 randomised phase 3 trial. Lancet Oncol. (2010) 11:927-33. doi: 10.1016/S1470-2045(10)70207-2

13. Kanyilmaz G, Aktan M, Koc M, Demir H, Demir LS. Unplanned irradiation of internal mammary lymph nodes in breast cancer. Radiol Med. (2017) 122:405-11. doi: 10.1007/s11547-017-0747-5 
14. Sapienza LG, Chen MJ, Gomes MJ, Mansur DB. Unintended irradiation of internal mammary chain - Is that enough? Rep Pract Oncol Radiother. (2016) 21:25-30. doi: 10.1016/j.rpor.2015.07.006

15. Arora D1, Frakes J, Scott J, Opp D, Johnson C, Song J, et al. Incidental radiation to uninvolved internal mammary lymph nodes in breast cancer. Breast Cancer Res Treat. (2015) 151:365-72. doi: 10.1007/s10549-015-3400-9

16. Chung Y, Kim JW, Shin KH, Kim SS, Ahn SJ, Park W, et al. Dummy run of quality assurance program in a phase 3 randomized trial investigating the role of internal mammary lymph node irradiation in breast cancer patients: Korean Radiation Oncology Group 08-06 study. Int J Radiat Oncol Biol Phys. (2015) 91:419-26. doi: 10.1016/j.ijrobp.2014.10.022

17. Leite ET, Ugino RT, Santana MA, Ferreira DV, Lopes MR, Pelosi EL, et al. Incidental irradiation of internal mammary lymph nodes in breast cancer: conventional two-dimensional radiotherapy versus conformal three-dimensional radiotherapy. Radiol Bras. (2016) 49:170-5. doi: 10.1590/0100-3984.2015.0003

18. Reznik J, Cicchetti MG, Degaspe B, Fitzgerald TJ. Analysis of axillary coverage during tangential radiation therapy to the breast. Int J Radiat Oncol Biol Phys. (2005) 61:163-8. doi: 10.1016/j.ijrobp.2004.04.065

19. Kataria T, Bisht SS, Gupta D, Goyal S, Jassal K, Abhishek A, et al. Incidental radiation to axilla in early breast cancer treated with intensity modulated tangents and comparison with conventional and 3D conformal tangents. Breast. (2013) 22:1125-9. doi: 10.1016/j.breast.2013.07.054

20. Aguiar A, Gomes Pereira H, Azevedo I, Gomes L. Evaluation of axillary dose coverage following whole breast radiotherapy: variation with the breast volume and shape. Radiother Oncol. (2015) 114:22-7. doi: 10.1016/j.radonc.2014.10.005

21. Lee J, Kim SW, Son SH. Dosimetric evaluation of incidental irradiation to the axilla during whole breast radiotherapy for patients with leftsided early breast cancer in the IMRT era. Medicine. (2016) 95:e4036. doi: 10.1097/MD.0000000000004036

22. Barry A, Rock K, Sole C, Rahman M, Pintilie, Lee G, et al. The impact of active breathing control on internal mammary lymph node coverage and normal tissue exposure in breast cancer patients planned for left-sided postmastectomy radiation therapy. Pract Radiat Oncol. (2017) 7:228-33. doi: $10.1016 /$ j.prro.2016.11.010

23. Veronesi U, Marubini E, Mariani L, Valagussa P, Zucali R. The dissection of internal mammary nodes does not improve the survival of breast cancer patients. 30-year results of a randomised trial. Eur J Cancer. (1999) 35:1320-5. doi: 10.1016/S0959-8049(99)00133-1

24. Verma V, Vicini F, Tendulkar RD, Khan AJ, Wobb J, Edwards-Bennett S, et al. Role of internal mammary node radiation as a part of modern breast cancer radiation therapy: a systematic review. Int J Radiat Oncol Biol Phys. (2016) 95:617-31. doi: 10.1016/j.ijrobp.2016.01.058

25. Nilsson G, Holmberg L, Garmo H, Terent A, Blomqvist C. Radiation to supraclavicular and internal mammary lymph nodes in breast cancer increases the risk of stroke. Br J Cancer. (2009) 100:811-6. doi: 10.1038/sj.bjc. 6604902
26. Wang W, Zhang Y, Xu M, Shao Q, Sun T, Yu T, et al. Postmastectomy radiotherapy using three different techniques: a retrospective evaluation of the incidental dose distribution in the internal mammary nodes. Cancer Manag Res. (2019) 11:1097-106. doi: 10.2147/CMAR.S 191047

27. Song Y, Yu T, Wang W, Li J, Sun T, Qiu P, et al. Dosimetric comparison of incidental radiation to the internal mammary nodes after breast-conserving surgery using 3 techniques-inverse intensity-modulated radiotherapy, fieldin-field intensity-modulated radiotherapy, and 3-dimensional conformal radiotherapy: a retrospective clinical study. Medicine. (2019) 98:e17549. doi: 10.1097/MD.0000000000017549

28. Proulx GM, Lee RJ, Stomper PC. Internal mammary lymph node inclusion in standard tangent breast fields: effects of body habitus. Breast J. (2001) 7:111-6. doi: 10.1046/j.1524-4741.2001.007002111.x

29. Hare GB, Proulx GM, Lamonica DM, Stomper PC. Internal mammary lymph node (IMN) coverage by standard radiation tangent fields in patients showing IMN drainage on lymphoscintigraphy: therapeutic implications. Am J Clin Oncol. (2004) 27:274-8. doi: 10.1097/01.coc.0000092596.03967.80

30. Wright P, Suilamo S, Lindholm P, Kulmala J. Isocentric integration of intensity-modulated radiotherapy with electron fields improves field junction dose uniformity in postmastectomy radiotherapy. Acta Oncol. (2014) 53:1019-26. doi: 10.3109/0284186X.2014.926027

31. Haciislamoglu E, Colak F, Canyilmaz E, Dirican B, Gurdalli S, Yilmaz $\mathrm{AH}$, et al. Dosimetric comparison of left-sided whole-breast irradiation with 3DCRT, forward-planned IMRT, inverse-planned IMRT, helical tomotherapy, and volumetric arc therapy. Phys Med. (2015) 31:360-7. doi: 10.1016/j.ejmp.2015.02.005

32. Schubert LK, Gondi V, Sengbusch E, Westerly DC, Soisson ET, Paliwal $\mathrm{BR}$, et al. Dosimetric comparison of left-sided whole breast irradiation with 3DCRT, forward-planned IMRT, inverse-planned IMRT, helical tomotherapy, and topotherapy. Radiother Oncol. (2011) 100:241-6. doi: 10.1016/j.radonc.2011.01.004

33. Sabater S, Gascon M, Gutierrez-Perez M, Berenguer R, Donovan EM, Harris EJ, et al. Influence of body habitus on dose parameters of nodal levels III to IV irradiation for breastcancer: comparison of 3 techniques. Med Dosim. (2018) 43:328-33. doi: 10.1016/j.meddos.2017.11.002

Conflict of Interest: The authors declare that the research was conducted in the absence of any commercial or financial relationships that could be construed as a potential conflict of interest.

Copyright (c) 2020 Wang, Wang, Qiu, Sun, Zhang, Shao, Xu, Liu and Li. This is an open-access article distributed under the terms of the Creative Commons Attribution License (CC BY). The use, distribution or reproduction in other forums is permitted, provided the original author(s) and the copyright owner(s) are credited and that the original publication in this journal is cited, in accordance with accepted academic practice. No use, distribution or reproduction is permitted which does not comply with these terms. 